\title{
Penerapan DFMA untuk Low Cost High Customization Product
}

\author{
Ilham Priadythama ${ }^{* 1)}$, Susy Susmartini ${ }^{2)}$, dan Alviandi Wahyu Nugroho ${ }^{3)}$ \\ ${ }^{123)}$ Program Studi S1 Teknik Industri, Fakultas Teknik, Universitas Sebelas Maret, \\ Jl. Ir. Sutami No.36 Jebres, Surakarta, 57126, Indonesia
}

\begin{abstract}
Design for Manufacturing and Assembly (DFMA) is a method to evaluate the design of product with considering the ease of manufacture process and the assembly process. UNS LPPD Hand is prosthetic hand with the function and shape that has likely the original hand man. UNS LPPD Hand is developed by the Laboratory Planning and Product Design of Sebelas Maret University (Laboratorium P3 UNS). From the conceptual design of prosthetic finger by Cahyadin (2016), the prototype can't do the movement flexed according with the design objectives and there are some components that not required. Therefore, there are some components that must be modified or eliminated. The modified component is phalanx of media and eliminated components are short and long pin holder The result is improvement of design prosthetic finger that 2 components are fixed and 4 components are eliminated, and reducing the process from 99 steps to 79 steps.
\end{abstract}

Keyword: Prosthetic Finger, UNS LPPD Hand, DFMA

\section{Pendahuluan}

Menurut Ulrich dan Eppinger (2001), fase dalam pengembangan dan perancangan produk terdiri dari fase perencanaan, fase pengembangan, fase perancangan tingkat sistem, fase perancangan rinci, fase pengujian dan perbaikan, dan fase peluncuran produk. Pada fase pengujian dan perbaikan, diperlukan proses evaluasi dari hasil rancangan produk tersebut. Hal itu bertujuan untuk memudahkan proses perakitan sehingga bisa mengurangi waktu perakitan dalam membuat satu produk. Salah satu metode yang dapat digunakan untuk proses evaluasi suatu rancangan yaitu metode Design for Manufacturing and Assembly (DFMA) (Kurnianto dkk., 2015). DFMA adalah suatu metode yang digunakan untuk mengevaluasi rancangan produk dengan mempertimbangkan kemudahan dalam proses manufaktur dan proses perakitan. Tujuan dari DFMA yaitu untuk menentukan desain produk yang benar-benar dapat menghilangkan komponen-komponen yang sebenarnya tidak diperlukan dan mengurangi proses dalam pembuatan prototipe (Hasibuan dkk., 2013).

Penelitian yang membahas tentang rancangan perbaikan produk dapat dilihat pada penelitian yang membuat rancangan perbaikan produk stopcontact melalui pendekatan metode DFMA (Hasibuan dik., 2013). Pada desain awal stopcontact 754 terdapat 47 unit komponen penysusun produk yang membutuhkan waktu 15,52 menit untuk menyelesaikan setiap unit produk. Setelah dilakukan perbaikan terhadap desain stopcontact 754 dengan menggunakan metode DFMA melalui proses perbaikan, kombinasi dan eliminasi dari komponen penyusun produk seperti baut 3323-A dan 3323-AP, lempeng tembaga 7544 serta lempeng tembaga 7545 , maka produk tersebut mengalami peningkatan dari segi waktu perakitan yaitu menjadi 12.484 menit untuk setiap unitnya yang terdiri dari 35 unit komponen, peningkatan pada effisiensi desain dan peningkatan pada jumlah produk standar yang dihasilkan adalah 33.64 unit. Hal ini menunjukkan bahwa perbaikan rancangan produk sangat berpengaruh terhadap lamanya waktu perakitan, biaya perakitan dan juga efisiensi perakitan.

*Correspondance : ilham@megaspin.net 
Pada penelitian ini, Design For Manufacturing and Assembly (DFMA) digunakan untuk membantu merancang produk dengan biaya yang rendah dan kustomisasi yang tinggi (low cost and high customization product), yaitu UNS LPPD Hand dan metode perakitan UNS LPPD Hand. UNS LPPD Hand adalah yaitu prosthetic hand yang memiliki fungsi dan bentuk seperti tangan asli manusia serta memiliki skema mekanik dan elektrik yang sederhana sehingga dapat dihasilkan dengan biaya yang terjangkau. DFMA juga dapat digunakan untuk membantu perancang dalam meningkatkan kualitas, mengurangi biaya perakitan, serta untuk mengukur perbaikan desain dari produk UNS LPPD Hand.

Berdasarkan fase pengembangan dan perancangan produk menurut Ulrich dan Eppinger (2001), pengembangan UNS LPPD Hand telah mencapai pada fase perancangan rinci, yaitu tahapan desain konseptual yang dikembangkan oleh Cahyadin (2016). Desain yang dibuat oleh Cahyadin (2016) merupakan desain yang detail, namun belum dipersiapkan dalam pembuatan prototipenya. Oleh karena itu, pada penelitian ini, akan dilakukan langkah pengembangan, yaitu fase pengujian dan perbaikan prototipe dari desain yang telah dibuat oleh Cahyadin (2016), sebelum dilakukan integrasi terhadap sistem kendali dan sistem mekanik sehingga prototipe UNS LPPD Hand yang telah dibuat dapat bergerak dengan menggunakan logika sederhana.

Prototipe berdasarkan desain Cahyadin (2016) telah dibuat dan hasilnya terdapat proses perakitan yang cukup sulit sehingga waktu perakitan menjadi lama. Selain itu, prototipe tidak dapat melakukan gerakan flexed sesuai tujuan perancangan. Pada penelitian ini diharapkan pendekatan metode Design for Manufacturing and Assembly dapat memberikan solusi yang tepat untuk perbaikan rancangan prototipe UNS LPPD Hand, sehingga menghasilkan perbaikan desain yang dapat dijadikan prototipe yang sesuai tujuan perancangan dan biaya pembuatan yang low cost.

\section{Metode Penelitian}

Adapun dalam penelitian ini digambarkan dalam metodologi sebagai berikut :

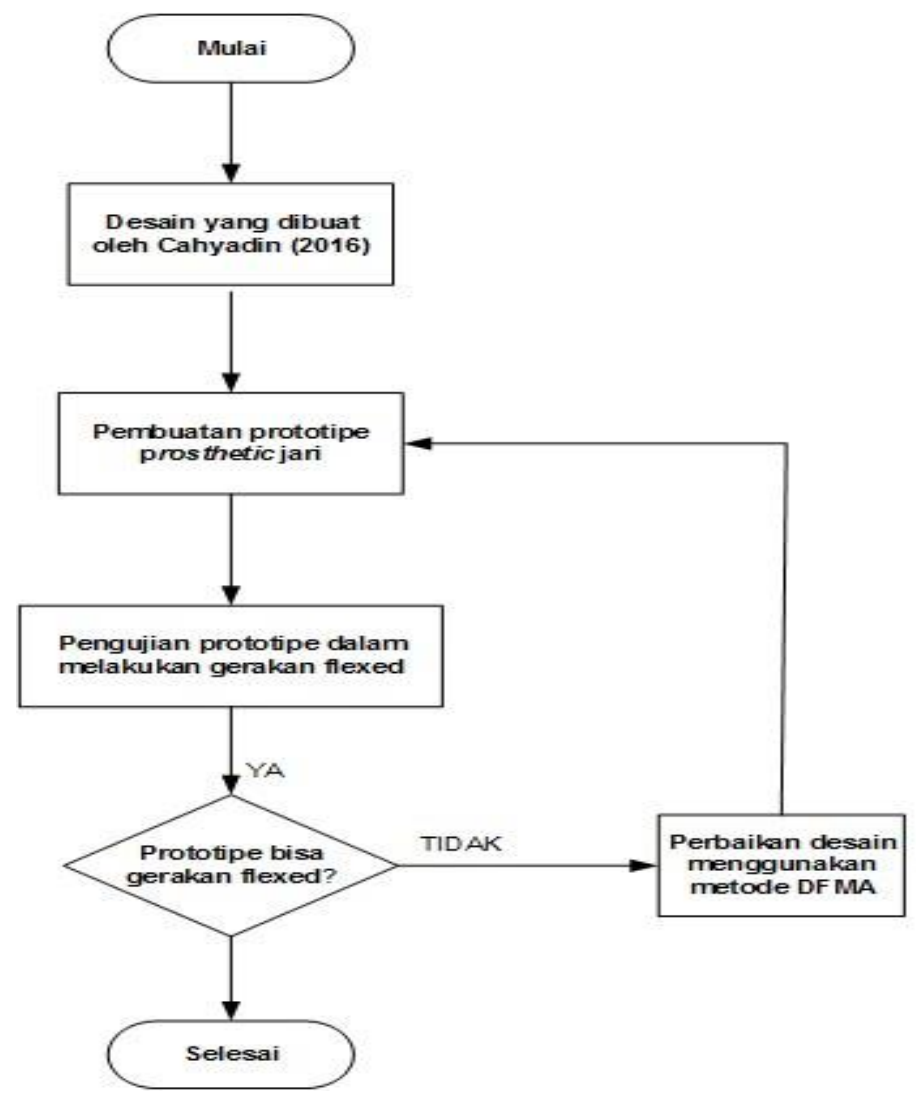

Gambar 1. Diagram Alir penelitian 


\subsection{Pembuatan Prototipe Prosthetic Jari}

Pada tahap ini dilakukan pembuatan prototipe prosthetic jari yang didasarkan pada desain yang telah dibuat oleh Cahyadin (2016). Adapun desain Cahyadin dapat dilihat pada gambar di bawah ini.

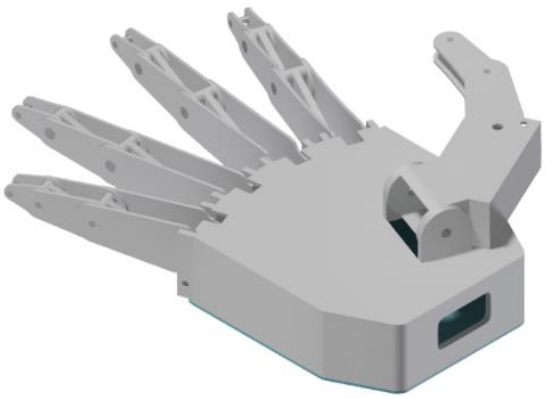

Gambar 2. Rancangan Prototipe Prosthetic Hand Sumber : Cahyadin (2016)

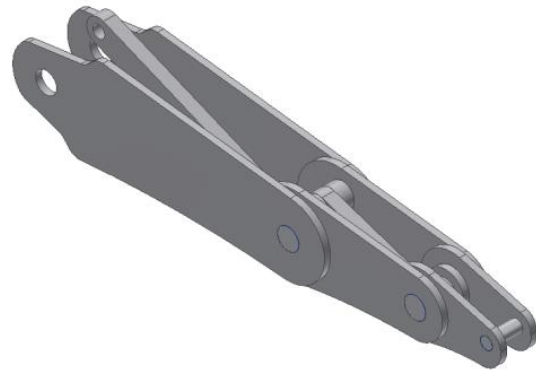

Gambar 3. Rancangan Prototipe Prosthetic Jari Sumber : Cahyadin (2016)

Adapun yang ingin dihasilkan dari tahap ini yaitu prototipe prosthetic jari yang bisa gerakan flexed dan extended seperti jari tangan manusia pada umumnya. Pembuatan prototipe prosthetic jari terdiri dari semua jari yaitu jari telunjuk, jari tengah, jari manis, jari kelingking dan ibu jari. Bahan yang digunakan untuk prototipe prosthetic jari yaitu PVC dengan ketebalan $2 \mathrm{~mm}$ dan besi silinder pejal dengan diameter $2 \mathrm{~mm}$. Peralatan yang digunakan yaitu scroll saw, rotary tool, dan hand drill.

Langkah-langkah pembuatan prototipe prosthetic jari yaitu:

1. Desain ditempelkan pada lembaran PVC kemudian dilakukan pemolaan.

2. PVC dilubangi dengan menggunakan hand drill dengan mata bor yang berdiameter 2 mm sesuai desain.

3. Lembaran PVC dipotong sesuai pola desain dengan menggunakan scroll saw dan dialuskan menggunakan rotary tool.

4. Besi silinder pejal (besi as) dipotong sesuai ukuran dengan menggunakan rotary tool.

5. Lembaran PVC dan besi silinder pejal yang telah dipotong sesuai ukuran kemudian dirakit menjadi prototipe prosthetic jari sesuai desain. bawah ini.

Prototipe prosthetic jari sesuai desain Cahyadin (2016) dapat dilihat pada gambar di

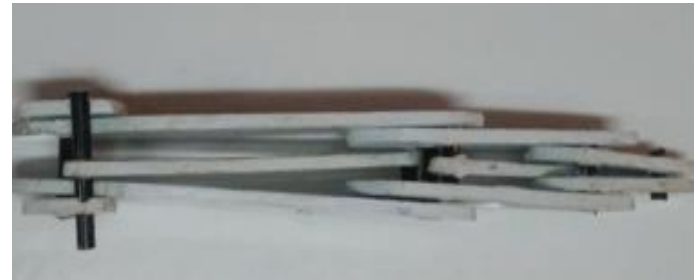

Gambar 4. Prototipe Prosthetic Jari 


\subsection{Pengujian Prototipe dalam melakukan Gerakan Flexed}

Pada tahap ini dilakukan pengujian prototipe dalam melakukan gerakan flexed. Setelah prototipe prosthetic jari selesai dibuat, prototipe tersebut diuji coba dalam melakukan gerakan flexed dan hasilnya prototipe tidak dapat bergerak sesuai dengan tujuan perancangan. Prototipe prosthetic jari sesuai desain Cahyadin (2016) dalam melakukan gerakan flexed dan gerakan flexed yang sesuai tujuan perancangan dapat dilihat pada gambar di bawah ini.

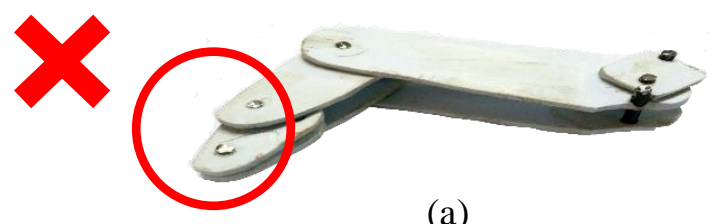

(a)

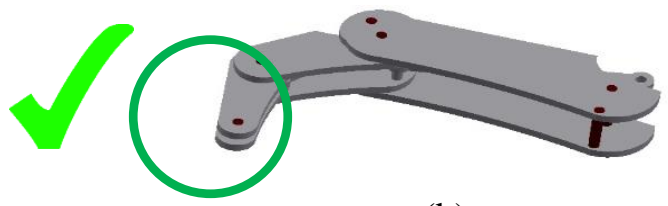

(b)

Gambar 5. Gerakan Flexed: (a) Prototipe Jari Sesuai Desain Cahyadin (2016) ;

(b) Sesuai Tujuan Perancangan

Prototipe yang telah dibuat tidak bisa bergerak sesuai tujuan perancangan. Untuk itu, dilakukan perbaikan desain prototipe dan pembuatan prototipe sesuai desain yang telah diperbaiki.

\subsection{Perbaikan Desain dengan Menggunakan Metode DFMA}

Pada tahap ini dilakukan perbaikan desain dengan menggunakan metode DFMA. Prototipe yang telah dibuat sesuai desain Cahyadin (2016) tidak dapat bergerak sesuai dengan tujuan perancangan. Untuk itu, dilakukan perbaikan rancangan prototipe jari agar prototipe dapat bergerak sesuai tujuan perancangan. Perbaikan rancangan dilakukan dengan melakukan proses eliminasi dan modifikasi komponen agar memudahkan dalam perakitan.

Dalam melakukan perbaikan perancangan, menurut Magrab (2010) ada beberapa prinsip yang harus dipenuhi untuk memperbaiki suatu proses perakitan antara lain adalah mengurangi dan meminimalisasi jumlah komponen, menggunakan komponen dengan bahan yang seragam, desain untuk kemudahan perakitan, desain untuk gabungan dan efisiensi fastener serta desain produk modular untuk perakitan (Hasibuan dkk., 2013).

Berdasarkan pada prinsip-prinsip tersebut menurut Boothroyd (2002) dapat dilakukan suatu perbaikan rancangan dengan menggunakan metode Design for Manufacturing and Assembly (DFMA) melalui pengembangan/modifikasi, kombinasi atau eliminasi komponen yang tidak diperlukan ataupun komponen yang tidak mengandung nilai tambah (Hasibuan dkk., 2013).

\section{Hasil dan Pembahasan}

\subsection{Prototipe Berdasarkan Desain Cahyadin (2016)}

Rancangan UNS LPPD Hand berdasarkan desain Cahyadin (2016) terdiri dari beberapa komponen. Komponen penyusun UNS LPPD Hand dapat dilihat pada gambar 6. 


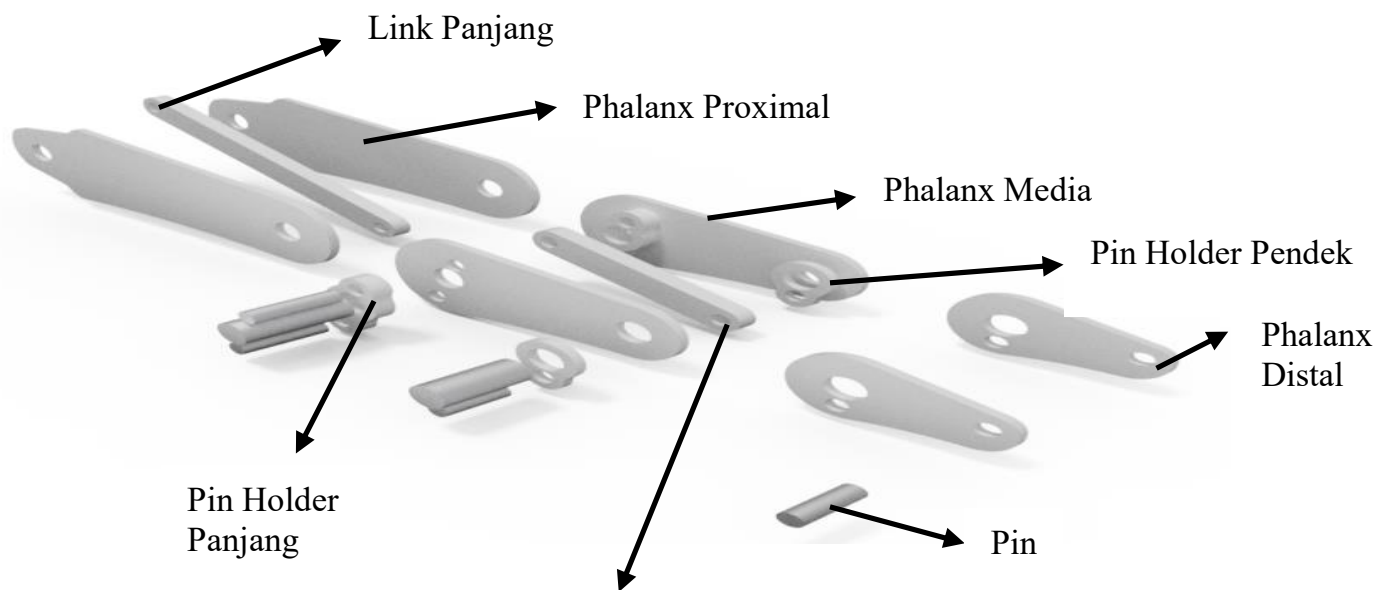

Link Pendek

Gambar 6. Komponen dalam Prosthetic Jari (Cahyadin, 2016)

Komponen prototipe prosthetic jari berdasarkan desain Cahyadin (2016) dapat dilihat pada Gambar 6. Komponen prototipe tersebut terdiri dari phalanx proximal, phalanx media, phalanx distal, link panjang, link pendek, pin holder panjang, pin holder pendek, dan pin. Adapun proses pembuatan setiap komponen dapat dilihat pada Tabel 1.

Tabel 1. Komponen dan Proses Prosthetic Jari Desain Cahyadin (2016)

\begin{tabular}{|c|c|c|c|c|c|}
\hline No. & Komponen & Material & $\begin{array}{c}\text { Jumlah } \\
\text { Komponen }\end{array}$ & Proses & Gambar \\
\hline \multirow{4}{*}{1} & \multirow{4}{*}{ Phalanx Proximal } & \multirow{4}{*}{ Lembaran PVC } & \multirow{4}{*}{2} & Menempelkan pola pada lembaran PVC & \\
\hline & & & & $\begin{array}{l}\text { Melubangi lembaran PVC dengan mata bor } \\
\text { yang berdiameter } 2 \mathrm{~mm} \text { sesuai pola }\end{array}$ & \\
\hline & & & & Memotong lembaran PVC sesuai desain & \\
\hline & & & & Menghaluskan permukaan hasil potongan & \\
\hline \multirow{4}{*}{2} & \multirow{4}{*}{ Phalanx Media } & \multirow{4}{*}{ Lembaran PVC } & \multirow{4}{*}{2} & Menempelkan pola pada lembaran PVC & \\
\hline & & & & $\begin{array}{l}\text { Melubangi lembaran PVC dengan mata bor } \\
\text { yang berdiameter } 2 \mathrm{~mm} \text { sesuai pola }\end{array}$ & \\
\hline & & & & Memotong lembaran PVC sesuai desain & \\
\hline & & & & Menghaluskan permukaan hasil potongan & \\
\hline \multirow{4}{*}{3} & \multirow{4}{*}{ Phalanx Distal } & \multirow{4}{*}{ Lembaran PVC } & \multirow{4}{*}{2} & Menempelkan pola pada lembaran PVC & \\
\hline & & & & $\begin{array}{l}\text { Melubangi lembaran PVC dengan mata bor } \\
\text { yang berdiameter } 2 \mathrm{~mm} \text { sesuai pola }\end{array}$ & \\
\hline & & & & Memotong lembaran PVC sesuai desain & \\
\hline & & & & Menghaluskan permukaan hasil potongan & \\
\hline \multirow{4}{*}{4} & \multirow{4}{*}{ Pin Holder Panjang } & \multirow{4}{*}{ Lembaran PVC } & \multirow{4}{*}{2} & Menempelkan pola pada lembaran PVC & \\
\hline & & & & $\begin{array}{l}\text { Melubangi lembaran PVC dengan mata bor } \\
\text { yang berdiameter } 2 \mathrm{~mm} \text { sesuai pola }\end{array}$ & \\
\hline & & & & Memotong lembaran PVC sesuai desain & \\
\hline & & & & Menghaluskan permukaan hasil potongan & \\
\hline \multirow{4}{*}{5} & \multirow{4}{*}{ Pin Holder Pendek } & \multirow{4}{*}{ Lembaran PVC } & \multirow{4}{*}{2} & Menempelkan pola pada lembaran PVC & \\
\hline & & & & $\begin{array}{l}\text { Melubangi lembaran PVC dengan mata bor } \\
\text { yang berdiameter } 2 \mathrm{~mm} \text { sesuai pola }\end{array}$ & \\
\hline & & & & Memotong lembaran PVC sesuai desain & \\
\hline & & & & Menghaluskan permukaan hasil potongan & \\
\hline \multirow{4}{*}{6} & \multirow{4}{*}{ Link Panjang } & \multirow{4}{*}{ Lembaran PVC } & \multirow{4}{*}{1} & Menempelkan pola pada lembaran PVC & \\
\hline & & & & $\begin{array}{l}\text { Melubangi lembaran PVC dengan mata bor } \\
\text { yang berdiameter } 2 \mathrm{~mm} \text { sesuai pola }\end{array}$ & \\
\hline & & & & Memotong lembaran PVC sesuai desain & \\
\hline & & & & Menghaluskan permukaan hasil potongan & \\
\hline \multirow{4}{*}{7} & \multirow{4}{*}{ Link Pendek } & \multirow{4}{*}{ Lembaran PVC } & \multirow{4}{*}{1} & Menempelkan pola pada lembaran PVC & \\
\hline & & & & $\begin{array}{l}\text { Melubangi lembaran PVC dengan mata bor } \\
\text { yang berdiameter } 2 \mathrm{~mm} \text { sesuai pola }\end{array}$ & \\
\hline & & & & Memotong lembaran PVC sesuai desain & \\
\hline & & & & Menghaluskan permukaan hasil potongan & \\
\hline \multirow{4}{*}{8} & \multirow{4}{*}{ Pin } & & & Mengukur besi as sesuai ukuran & \\
\hline & & Besi As & 8 & Memberi tanda pada besi as setelah diukur & \\
\hline & & Dest As & 0 & Memotong besi as sesuai ukuran & \\
\hline & & & & Menghaluskan permukaan hasil potongan & \\
\hline
\end{tabular}


Dari tabel di atas, jumlah keseluruhan komponen yang dibutuhkan dalam pembuatan prototipe prosthetic jari yaitu sebanyak 20 komponen. Total keseluruhan proses pembuatan komponen yaitu sebanyak 80 proses. Setelah setiap komponen dibuat, langkah selanjutnya yaitu perakitan setiap komponen menjadi prototipe prosthetic jari. Adapun proses perakitan setiap komponen dapat dilihat pada Tabel 2.

Tabel 2. Urutan Perakitan Prosthetic Jari Desain Cahyadin (2016)

\begin{tabular}{|c|c|c|}
\hline No. & Proses & Urutan Perakitan \\
\hline 1 & \multirow{6}{*}{$\begin{array}{l}\text { Sub-Assembly } \\
\text { Phalanx Distal }\end{array}$} & Memasang pin pada phalanx distal \\
\hline 2 & & Memasang pin holder pendek \\
\hline 3 & & Memasang pin \\
\hline 4 & & Memasang link pendek \\
\hline 5 & & Memasang pin holder pendek \\
\hline 6 & & Memasang phalanx distal \\
\hline 7 & \multirow{8}{*}{$\begin{array}{l}\text { Sub-Assembly } \\
\text { Phalanx Media }\end{array}$} & Memasang phalanx media pada sub-assembly phalanx distal \\
\hline 8 & & Memasang pin \\
\hline 9 & & Memasang pin holder panjang \\
\hline 10 & & Memasang pin \\
\hline 11 & & Memasang link panjang \\
\hline 12 & & Memasang pin \\
\hline 13 & & Memasang pin holder panjang \\
\hline 14 & & Memasang phalanx media \\
\hline 15 & \multirow{5}{*}{$\begin{array}{c}\text { Sub-Assembly } \\
\text { Phalanx Proximal }\end{array}$} & Memasang phalanx proximal pada sub-assembly phalanx media \\
\hline 16 & & Memasang pin \\
\hline 17 & & Memasang pin \\
\hline 18 & & Memasang pin \\
\hline 19 & & Memasang phalanx proximal \\
\hline
\end{tabular}

Berdasarkan tabel di atas, diketahui bahwa jumlah proses perakitan komponen penyusun prototipe prosthetic jari yaitu sebanyak 19 proses.

\subsection{Hasil Perancangan menggunakan DFMA}

Dalam melakukan perbaikan perancangan, menurut Magrab (2010) ada beberapa prinsip yang harus dipenuhi untuk memperbaiki suatu proses perakitan antara lain adalah mengurangi dan meminimalisasi jumlah komponen, menggunakan komponen dengan bahan yang seragam, desain untuk kemudahan perakitan, desain untuk gabungan dan efisiensi fastener serta desain produk modular untuk perakitan (Hasibuan dkk., 2013).

Berdasarkan pada prinsip-prinsip tersebut menurut Boothroyd (2002) dapat dilakukan suatu perbaikan rancangan dengan menggunakan metode Design for Manufacturing and Assembly (DFMA) melalui pengembangan/modifikasi, kombinasi atau eliminasi komponen yang tidak diperlukan ataupun komponen yang tidak mengandung nilai tambah (Hasibuan dkk., 2013). Pada Tabel 2. akan diuraikan komponen-komponen yang dapat dikembangkan, kombinasi ataupun dieliminasi dari prototipe prosthetic jari.

Tabel 3. Komponen yang Dimodifikasi dan Dieliminasi

\begin{tabular}{|c|l|c|}
\hline No & Nama Komponen & Jumlah Komponen \\
\hline 1 & Phalanx Media & 2 \\
\hline 2 & Pin Holder Pendek & 2 \\
\hline 3 & Pin Holder Panjang & 2 \\
\hline
\end{tabular}

Pada konsep desain awal prototipe prosthetic jari, ada bagian dari komponen phalanx media yang menghalangi link pendek untuk terhubung dengan phalanx proximal, sehingga menyebabkan pada bagian antara phalanx media dengan phalanx distal tidak dapat melakukan 
gerakan flexed. Untuk itu, dilakukan modifikasi pada komponen phalanx media agar dapat menyelesaikan masalah gerakan flexed tersebut. Adapun gambar hasil rancangan dari phalanx media yang telah dimodifikasi dapat dilihat pada Gambar 7.

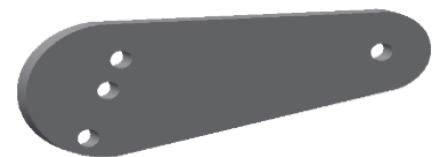

(a)

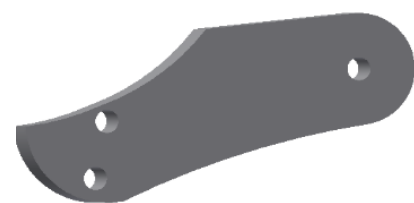

(b)

Gambar 7. Rancangan Phalanx Media : (a) Cahyadin (2016) ; (b) Hasil Perbaikan

Selain itu, juga ada komponen pin holder pendek dan pin holder panjang pada konsep desain awal. Komponen tersebut dipasang pada phalanx media yang terhubung dengan phalanx proximal dan phalanx distal. Setelah dibuat prototipe, komponen pin holder panjang dan pendek yang terletak di antara link dengan phalanx (ruas) menyebabkan pergerakan prototipe prosthetic jari menjadi berat dikarenakan besarnya gaya gesek yang terdapat pada prototipe. Untuk itu dilakukan perbaikan prototipe prosthetic jari dengan menghilangkan komponen pin holder panjang dan pendek.

Menurut Eggert (2005), berdasarkan rekomendasi dari The Society of Manufacturing Engineers (SME) untuk memperbaiki rancangan dari komponen pin holder pendek dan pin holder panjang, ada beberapa prinsip yang dapat digunakan. Adapun prinsip-prinsip tersebut antara lain adalah "meminimalkan jumlah komponen, menggunakan perakitan modular atau menggunakan komponen standar sehingga tidak banyak variasi komponen" (Hasibuan dkk., 2013). Maka berdasarkan pada prinsip tersebut dilakukan perbaikan terhadap rancangan dengan mengeliminasi komponen pin holder pendek dan pin holder panjang, sehingga dapat mengurangi jumlah serta variasi dari komponen yang akan dirakit yang bertujuan agar dapat mempercepat proses perakitan.

Berdasarkan identifikasi terhadap komponen penyusun prototipe prosthetic jari yang telah dilakukan, ternyata ada beberapa komponen yang dapat diperbaiki maupun dieliminasi untuk mengoptimalkan proses perakitan dari segi jumlah komponen dan proses. Hal ini sejalan dengan metode kerja perakitan prototipe prosthetic jari yang belum optimal karena masih ada beberapa elemen kegiatan yang sebenarnya tidak diperlukan pada saat proses perakitan berlangsung.

Pada desain awal prototipe prosthetic jari terdapat 20 unit komponen penyusun prototipe. Setelah dilakukan perbaikan terhadap desain prototipe prosthetic jari dengan menggunakan metode DFMA melalui proses perbaikan dan eliminasi dari komponen penyusun produk seperti phalanx media, pin holder panjang, dan pin holder pendek maka produk tersebut pengurangan jumlah komponen menjadi 16 unit. Selain itu, dari pengurangan jumlah komponen sebanyak 2 pin holder panjang dan 2 pin holder pendek mengakibatkan jumlah proses pembuatan komponen berkurang sebanyak 16 proses. Adapun keterangannya dapat dilihat pada Tabel 3.

Tabel 4. Perbandingan Desain Cahyadin (2016) dengan Hasil DFMA

\begin{tabular}{|c|l|c|c|c|}
\hline No. & \multicolumn{1}{|c|}{ Desain } & $\begin{array}{c}\text { Jumlah Komponen } \\
\text { (unit) }\end{array}$ & $\begin{array}{c}\text { Jumlah Proses } \\
\text { Pembuatan } \\
\text { Komponen }\end{array}$ & $\begin{array}{c}\text { Jumlah Proses } \\
\text { Perakitan }\end{array}$ \\
\hline 1 & Cahyadin (2016) & 20 & 80 & 19 \\
\hline 2 & Hasil DFMA & 16 & 64 & 15 \\
\hline
\end{tabular}




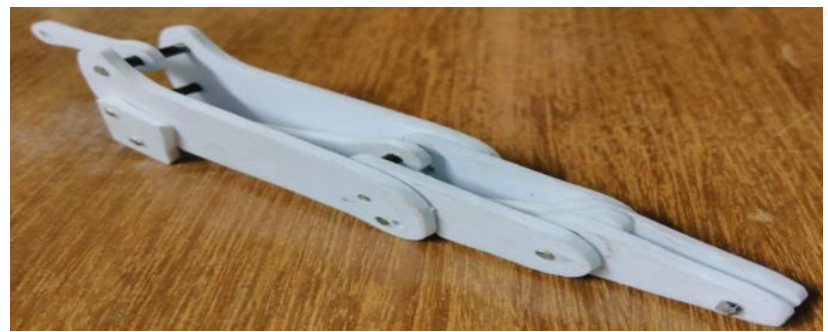

Gambar 8. Prototipe Prosthetic Jari Hasil DFMA

Hasil perbaikan yang didapat yaitu prototipe prosthetic jari dapat melakukan gerakan flexed yang sesuai tujuan perancangan. Gerakan flexed yang dilakukan phalanx proximal membuat phalanx media dan phalanx distal bergerak secara bersamaan mengikuti arah gerakan phalanx proximal. Setelah dilakukan perbaikan, komponen yang dibutuhkan untuk membuat prototipe prosthetic jari menjadi berkurang, proses pembuatan komponen pun menjadi berkurang, waktu perakitan pun menjadi lebih cepat. Hal tersebut dapat mengurangi biaya yang dibutuhkan dalam proses pembuatan prototipe prosthetic jari.

\section{Simpulan}

Setelah membuat perbaikan desain prototipe prosthetic jari dan melakukan analisis diperoleh kesimpulan yaitu hasil perbaikan desain prototipe prosthetic jari terdiri dari 16 komponen penyusun dengan adanya beberapa komponen yang diperbaiki maupun dieliminasi. Jumlah proses pembuatan komponen yang pada awalnya berjumlah 80 proses berubah menjadi 64 proses. Jumlah proses perakitan yang pada awalnya berjumlah 19 proses berubah menjadi 15 proses. Hasil rancangan tersebut membuat proses perakitan menjadi lebih mudah dan cepat. Dengan hasil rancangan tersebut, diharapkan pada penelitian selanjutnya, pembuatan prototipe menjadi lebih mudah dalam proses perakitannya dan lebih cepat dari rancangan sebelumnya, sehingga biaya perakitan prototipe prosthetic jari menjadi lebih murah dari desain sebelumnya.

\section{Daftar Pustaka}

Cahyadin, J. B. (2016). Skripsi: Visualisasi dan Verifikasi Konsep Desain UNS LPPD HAND Hand Menggunakan CAD/CAE. Fakultas Teknik, Program Studi Teknik Industri, Universitas Sebelas Maret Surakarta.

Dechev, N., Cleghorn W.L., dan Naumann, S. (2001). Multiple Finger, Passive Adaptive Grasp Prosthetic Hand. Mechanism and Machine Theory, 36, 1157-1173.

Fukuya, N., Toyama, S., Asfour, T., \& Dillmann, R. (2001). Design of a Humanoid Hand for Human Friendly Robotics Application. Human Friendly Mechatronics, 6, 273-278.

Hasibuan, Y.K., Rambe, A.J.M., \& Ginting, R., (2013). Rancangan Perbaikan Stopcontact Melalui Pendekatan Metode DFMA (Design For Manufacturing And Assembly) Pada PT. XYZ. E-Jurnal Teknik Industri FT USU. Vol. 1, No. 2, pp. 34-39.

Kurnianto, R.R., Wibowo, A., \& Prakosa, T. (2015). Penerapan Metoda Design for Manufacture and Assembly pada Handle Transformer Hand Bike. Prosiding Seminar Nasional Tahunan Teknik Mesin XIV.

Martell, J.W.S. \& Giuseppina, G. (2007). Robotic Hands: Design Review and Proposal of New Design Process. International Journal of Mechanical, Aerospace, Industrial, Mechatronic and Manufacturing Engineering, 1, 57-62.

Susmartini, S., Priadythama, I. \& Herdiman, L. (2011). Pemilihan Desain Prosthetic Jari Tangan Berdasarkan Mekanisme Sistem Penggerak Cross Bar dan Cross Cable terhadap Besar Gaya Tarik Dinamis Prosthetic Jari Tangan. Performa, Vol. 10, No. 2, pp. 141-148.

Ulrich, K.T., \& Eppinger, S.D. (2001). Perancangan dan Pengembangan Produk. Jakarta: Salemba Teknika. 